\title{
Computational Study Reliability of Diesel Engine through Electrical Assembly
}

\section{Sunil Bhardwaj ${ }^{1}$, Nitin Bhardwaj², Vijay Kumar ${ }^{3}$, Bhupender Parashar ${ }^{4}$, Mohit Kumar Kakkar ${ }^{5 *}$, Jasdev Bhatti ${ }^{5}$}

\author{
${ }^{1}$ Amity University Haryana, Gurugram, Haryana, INDIA \\ ${ }^{2}$ Chaudhary Charan Singh Haryana Agricultural University, Hisar, Haryana, INDIA \\ ${ }^{3}$ Amity University Haryana, Gurugram Haryana, INDIA \\ ${ }^{4}$ JSS Academy of Technical Education Noida, INDIA \\ ${ }^{5}$ Chitkara University Institute of Engineering and Technology, \\ Chitkara University, Punjab, INDIA \\ *Corresponding Author
}

DOI: https://doi.org/10.30880/ijie.2021.13.06.015

Received 6 April 2020; Accepted 28 July 2021; Available online 31 August 2021

\begin{abstract}
Diesel engine's complexity is a primary cause of breakdown or inability. Engine failure impacts device performance and thus efficiency. It often increases the cost of maintenance as the system goes down again and again. The main aim of this analysis is therefore to concentrate on aspects of the reliability and availability of diesel locomotive engines. For this reason, a large collection of observations is explored to evaluate the availability output of electrical assembly components. Weibull distribution is then used to analyse the reliability of the system and the rate of failure information that can be used in the rail industry to minimize unforeseen failures and to increase the reliability as well as the availability of diesel locomotives. A comparative study of Weibull distribution with the other distribution has been carried out to show the benefits of the Weibull distribution.
\end{abstract}

Keywords: Reliability, diesel locomotive engine, electrical assembly, weibull distribution, minitab19

\section{Introduction}

Consistency of a system is the probability that, under defined operational and environmental conditions, the device can perform a specific function at the end over a specified time [Dinkar et al. 2018]. Reliability must be defined by definitive norm based on many variables, maximum of that may random [Bhardwaj et al. (2018)]. Reliability is arduous to scale, because no such tool is there to do this for specific machine. The reliability of the diverse units of complex machinery depends on their output process, the standard of the composites used in their design, operating conditions, etc. Despite these criteria the reliability of the system is very much related to diverse forms of uncertainty. The numerical assessment of ambiguities is therefore the starting point for a numerical assessment of reliability [Bhardwaj et al. (2019)]. The theory of probability is a concept concerned with the analysis of risk [Li, Y. - F et al. 2006]. Maintenance regulations can address issues pertaining to general maintenance, fix or dump laws, rules on emergency reporting, inventory control, supply of spare parts, etc. Such maintenance policies may be defined in advance and implementation decisions may be taken accordingly. The 
design process involves unit length assessments, research protocols, degree of automation as well as integrated redundancies, test time, specific test facilities and measures for safety; and so forth [Allan, T.M., 2012]. Performance is an attribute of reliability to reparable systems which accounts for the quality and service property of a component or device. ABC appraisal seeks to distinguish the item from each other and decide the importance of the element and the degree as required by company.

\section{Different Parts of Engine used in Locomotive}

Figure 1 displays a diesel engine used by the railroad locomotive. The engine form is shaped by ' $\mathrm{V}$ ' and has 16 cylinders [India Railways Maintenance Manual for Diesel Locomotives, 2013]. These are arranged in pairs, each pair of cylinders using a homo-logic crankshaft cast.

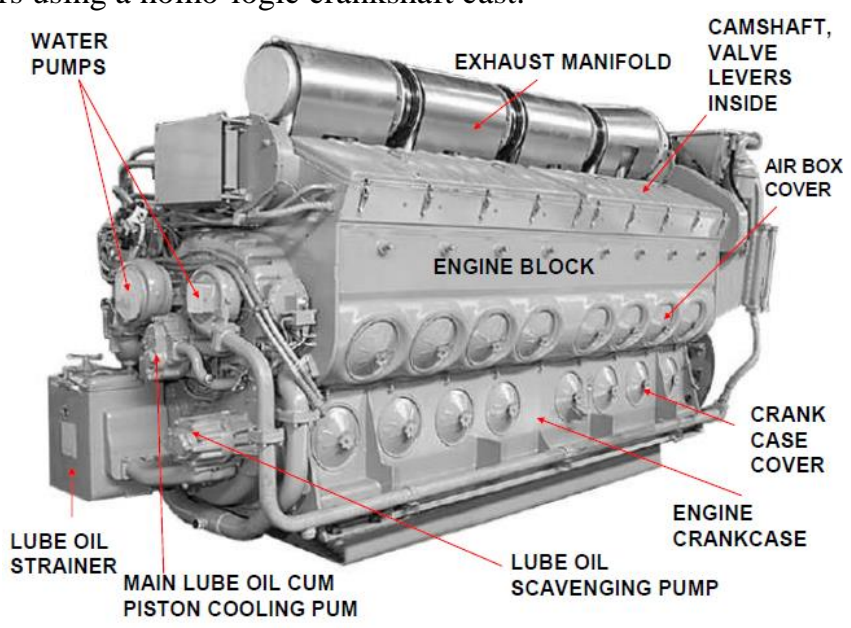

Fig. 1 - Different parts of V - Shaped diesel engine structure (Source: A brief record on diesel locomotive at diesel loco shed - Siliguri Diesel Loco Shed, Aditya Bhttacharjee)

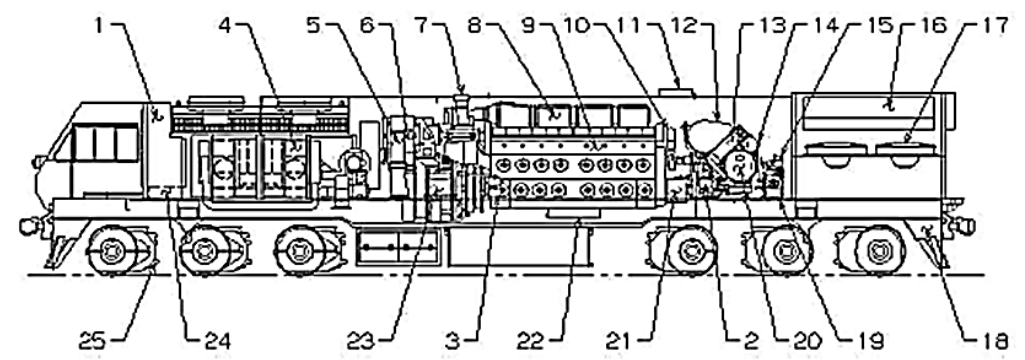

1) Electrical Control Cabinet
2) Fuel Pump
3) Engine Starting Motors
4) Traction Control Cabinet
5) Traction Motor Cooling Air Blower
6) Main Generator/Companion Alternator Blower
7) Engine Exhaust Stack
8) Engine Exhaust Manifold
9) 16-710G3B Diesel Engine
10) Governor
11) Engine room Vent
12) Engine Water Tank
13) Lube Oil Cooler

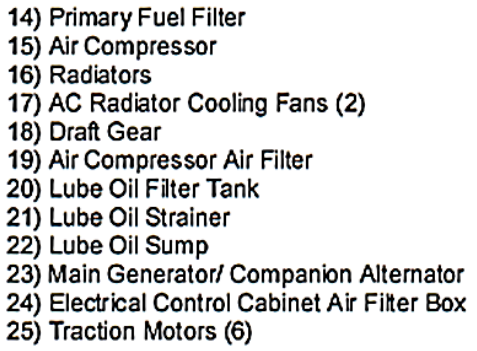

Fig. 2 - Railway diesel locomotive engine (Source: Introduction Hand Book on General Motor Diesel Locomotive, Ministry of Railways, Govt. of INDIA, IRCAMTECH/2006/M/D/GM loco/1.0, pp - 20)

\section{Failure}

Non - availability of a component is termed as failure. The reason of a failure of the components is different; they may failed because they were randomly selected and tagged as failing to test the respective effect, or they could fail because of any additional component that relied on other components has broken down. A failure is called in reliability engineering when a subsystem/ system fail to perform its desirable function and is deemed inaccessible [Venkatesh, M., 2012]. The definition of failure for a specific system can change over time. 
Field failures usually don't arise on a consistent rate although obey the time cycle usually described by "bathub curve" as shown in Figure 3. System's lifetime may be categorized into three areas: Infant Mortality Age, when the failure rate slowly increases; Useful Life Time, when the failure rate remains at steady state; and Wear out Phase, when the failure rate starts to rise [Bhardwaj et. al 2019]. There is a small sub-group of units within a unit population of latent defects that malfunction when subjected to stimuli that, otherwise be advantageous to a strong system. The remaining population is more competitive with the elimination of the weak units, and the failure rate is known to decrease. Units that cross the infant mortality span are very likely to survive the mechanism and its conditions in the environment [Tomas Skrucany et al. 2019]. Shortfalls that exist during Useful Life are latent defects that endure infant mortality, irregular systems or environmental conditions or premature wear.

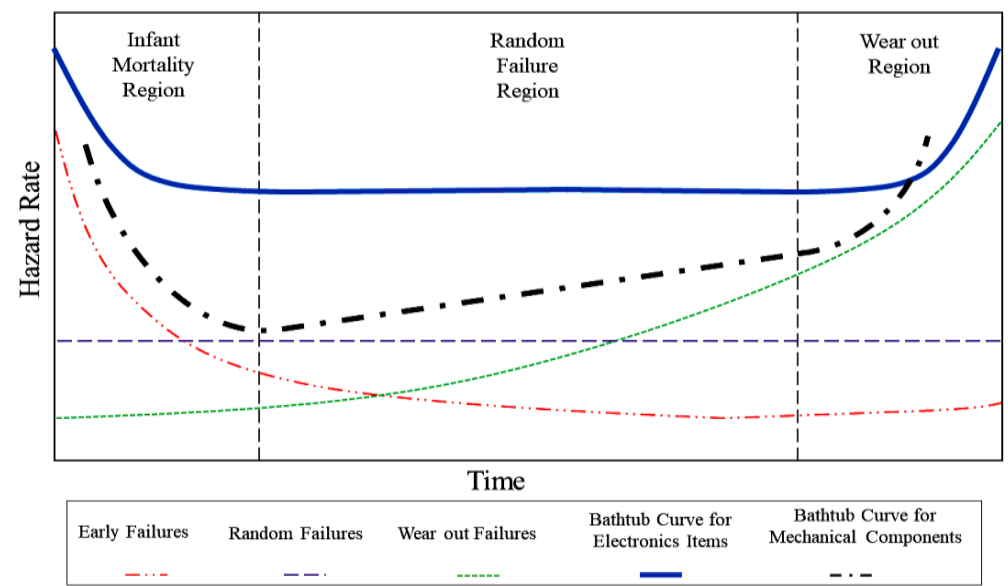

Fig. 3 - Bathtub curve for the system having mechanical and electronics assembly [Shazaib Ahsan et al. 2019]

\section{Estimation of Reliability}

Reliability estimation is clearly to analyse components and sections with the goal of predicting and calculating the failure rate of an item. One of the most common forms of reliability analysis for deciding failure rate and MTBF, MTTR, Availability, etc., is a reliability predictor.

\subsection{MTTF: Mean Time to Failure}

If one item is operational, it is the expected time $t$ value or the TTF (Time to Failure) mean distribution. If and only if failure rate is at steady state or $\lambda=\lambda(t)$ then

$$
M T T F=\int_{0}^{\infty} R(t) d t=\int_{0}^{\infty} e^{-\lambda t} d t=\frac{1}{\lambda}
$$

\subsection{MTBF:}

It's the anticipated mean period amid incidents of failure that allows the object to deteriorate. MTBF may therefore be defined as the mean - time that an element runs without failure (usually in hours) If and only if the item does have a steady rate of failure, then,

$$
M T B F=\int_{0}^{\infty} R(t) d t=\frac{1}{\lambda}
$$

\section{Data Collection}

The first and most essential prerequisite for reliability and for detecting or restoring errors is the accuracy of the data. Data is collected for the present assessment on Railway Diesel Locomotive Engine, its electrical system faults over the last five years, i.e. January 2012 to December 2016, as shown in Table 1. This report contains no. of failures related to various types of Diesel Locomotive Engine systems or device failures and 
their monthly or annual failures, part or device malfunction, cause of failure and previously taken corrective actions.

Table 1 - Failure data of diesel engine 2012 - 2016; electrical system (electrical control cabinet)

\begin{tabular}{|c|c|c|c|c|c|c|}
\hline $\begin{array}{l}\text { S. } \\
\text { No. }\end{array}$ & Year & Month & $\begin{array}{c}\text { Monthly } \\
\text { Operating Time } \\
\text { (hours) }\end{array}$ & $\begin{array}{c}\text { No. of } \\
\text { Failures }\end{array}$ & $\begin{array}{l}\text { Percentage } \\
\text { of Failures }\end{array}$ & $\begin{array}{c}\text { Cumulative \% } \\
\text { Failures }\end{array}$ \\
\hline 1 & \multirow{12}{*}{2012} & Jan & 706 & 0 & 0 & 0 \\
\hline 2 & & Feb & 608 & 0 & 0 & 0 \\
\hline 3 & & Mar & 564 & 0 & 0 & 0 \\
\hline 4 & & Apr & 588 & 0 & 0 & 0 \\
\hline 5 & & May & 694 & 0 & 0 & 0 \\
\hline 6 & & Jun & 686 & 1 & 20 & 20 \\
\hline 7 & & Jul & 719 & 0 & 0 & 20 \\
\hline 8 & & Aug & 719 & 0 & 0 & 20 \\
\hline 9 & & Sept & 635 & 0 & 0 & 20 \\
\hline 10 & & Oct & 719 & 0 & 0 & 20 \\
\hline 11 & & Nov & 659 & 0 & 0 & 20 \\
\hline 12 & & Dec & 657 & 0 & 0 & 20 \\
\hline 13 & \multirow{12}{*}{2013} & Jan & 710 & 0 & 0 & 20 \\
\hline 14 & & Feb & 672 & 0 & 0 & 20 \\
\hline 15 & & Mar & 717 & 0 & 0 & 20 \\
\hline 16 & & Apr & 625 & 0 & 0 & 20 \\
\hline 17 & & May & 719 & 2 & 40 & 40 \\
\hline 18 & & Jun & 696 & 0 & 0 & 60 \\
\hline 19 & & Jul & 647 & 0 & 0 & 60 \\
\hline 20 & & Aug & 696 & 0 & 0 & 60 \\
\hline 21 & & Sept & 694 & 0 & 0 & 60 \\
\hline 22 & & Oct & 729 & 0 & 0 & 60 \\
\hline 23 & & Nov & 612 & 0 & 0 & 60 \\
\hline 24 & & Dec & 719 & 0 & 0 & 60 \\
\hline 25 & \multirow{12}{*}{2014} & Jan & 682 & 0 & 0 & 60 \\
\hline 26 & & Feb & 588 & 0 & 0 & 60 \\
\hline 27 & & Mar & 718 & 0 & 0 & 60 \\
\hline 28 & & Apr & 694 & 0 & 0 & 60 \\
\hline 29 & & May & 706 & 0 & 0 & 60 \\
\hline 30 & & Jun & 682 & 0 & 0 & 60 \\
\hline 31 & & Jul & 719 & 0 & 0 & 60 \\
\hline 32 & & Aug & 704 & 0 & 0 & 60 \\
\hline 33 & & Sep & 696 & 0 & 0 & 60 \\
\hline 34 & & Oct & 659 & 1 & 20 & 80 \\
\hline 35 & & Nov & 696 & 0 & 0 & 80 \\
\hline 36 & & Dec & 729 & 0 & 0 & 80 \\
\hline 37 & \multirow{12}{*}{2015} & Jan & 588 & 0 & 0 & 80 \\
\hline 38 & & Feb & 588 & 0 & 0 & 80 \\
\hline 39 & & Mar & 706 & 0 & 0 & 80 \\
\hline 40 & & Apr & 564 & 0 & 0 & 80 \\
\hline 41 & & May & 729 & 0 & 0 & 80 \\
\hline 42 & & Jun & 682 & 0 & 0 & 80 \\
\hline 43 & & Jul & 588 & 0 & 0 & 80 \\
\hline 44 & & Aug & 706 & 0 & 0 & 80 \\
\hline 45 & & Sept & 706 & 0 & 0 & 80 \\
\hline 46 & & Oct & 682 & 0 & 0 & 80 \\
\hline 47 & & Nov & 659 & 0 & 0 & 80 \\
\hline 48 & & Dec & 719 & 0 & 0 & 80 \\
\hline 49 & & Jan & 717 & 0 & 0 & 80 \\
\hline 50 & & Feb & 564 & 0 & 0 & 80 \\
\hline
\end{tabular}




\begin{tabular}{|c|c|c|c|c|c|c|}
\hline 51 & & Mar & 141 & 0 & 0 & 80 \\
\hline 52 & & Apr & 541 & 1 & 20 & 100 \\
\hline 53 & & May & 494 & 0 & 0 & 100 \\
\hline 54 & 2016 & Jun & 635 & 0 & 0 & 100 \\
\hline 55 & & Jul & 706 & 0 & 0 & 100 \\
\hline 56 & & Aug & 682 & 0 & 0 & 100 \\
\hline 57 & & Sept & 588 & 0 & 0 & 100 \\
\hline 58 & & Oct & 588 & 0 & 0 & 100 \\
\hline 59 & & Nov & 635 & 0 & 0 & 100 \\
\hline 60 & & Dec & 717 & 0 & 0 & 100 \\
\hline
\end{tabular}

Report of the diesel engine failure as shown in Table $3 \&$ Figure 4, daily breakdown information from the diesel locomotive shed's daily maintenance statistics laboratory.

Table 3 - No. of failures of electrical misc

\begin{tabular}{cc}
\hline Particulars & No. of Failures \\
\hline Electrical System (Electrical Control Cabinet) & 05 \\
\hline
\end{tabular}

It has been found from the study that the damaging of electrical control cabinet wire is the primary concern of the failure of electrical components

- Failure of current measure sensor

- Damage of Electrical Control Cabinet wire due to rubbing with outer drum of electrical control cabinet.

- Ground Relay (GR1) Wire No. 6 inters lock less over travel

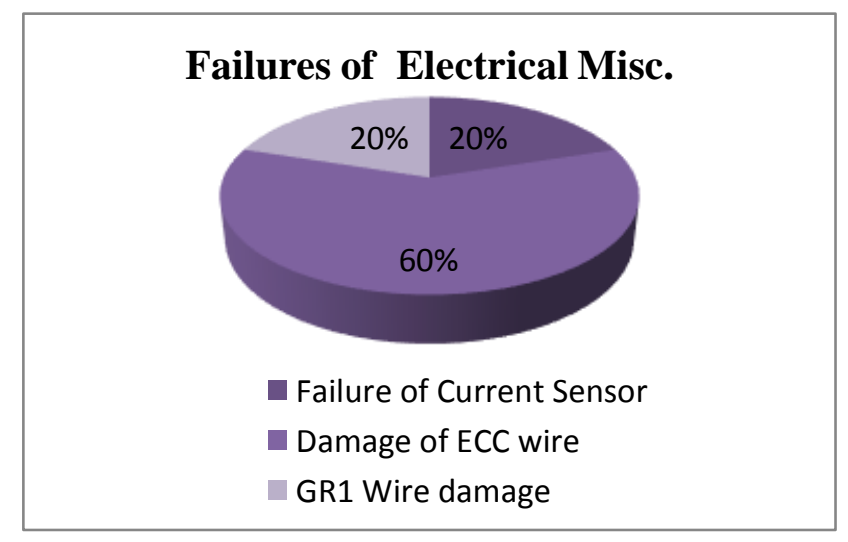

Fig. 4 - Failures of electrical miscellaneous

\section{Fitting of Distribution to the Data}

With computation analysis of the failure data through MINITAB 19, it is clear that the coefficient of correlation of Weibull distribution is more significant than Lognormal, Exponential and Normal distribution as in table 1. Therefore, Weibull distribution would be the best fit for the data. From the table 4, Weibull distribution provide reasonable fit for the failure data based on probability plots in figure 5 and $\mathrm{p}-$ values.

Table 4 - Goodness-of-Fit [Anderson et al., 2010]

\begin{tabular}{lll}
\hline Distribution & $\begin{array}{l}\text { Anderson-Darling } \\
\text { (adj) }\end{array}$ & $\begin{array}{l}\text { Correlation } \\
\text { Coefficient }\end{array}$ \\
Weibull & 87.332 & 0.946 \\
Lognormal & 87.334 & 0.919 \\
Exponential & 87.365 & $*$ \\
Normal & 87.333 & 0.932 \\
\hline
\end{tabular}


Table 5 - Table of Percentiles

\begin{tabular}{lll}
\hline Distribution & Percent & $\begin{array}{l}\text { Percentile } \\
\text { Weibull }\end{array}$ \\
Lognormal & 1 & 560.766 \\
Exponential & 1 & 50.5468 \\
Normal & 1 & 560.158 \\
Weibull & 5 & 647.689 \\
Lognormal & 5 & 642.895 \\
Exponential & 5 & 257.973 \\
Normal & 5 & 646.595 \\
& & \\
Weibull & 10 & 695.755 \\
Lognormal & 10 & 691.837 \\
Exponential & 10 & 529.896 \\
Normal & 10 & 692.674 \\
& & \\
Weibull & 50 & 839.114 \\
Lognormal & 50 & 896.197 \\
Exponential & 50 & 3486.09 \\
Normal & 50 & 855.217 \\
\hline
\end{tabular}

\subsection{Weibull Distribution}

The Weibull distribution (WD) is a very widely used distribution to analyse the lifetime of a system in the area of reliability engineering and machines. It is a multilateral distribution that may take on the characteristics of alternative types of distributions, with different values of $\beta$ [Emad et al. 2013].

6.2 Definition for Probability Density Function: Let $X$, be a random variable and let $\eta, \beta>0$, then $\mathrm{X}$ is said to be Weibull Distributed with parameter $\eta$ and $\beta$ if the Probability Density Function of $\mathrm{X}$ is

$f(x: \eta, \beta)=\left\{\begin{array}{cl}\frac{\beta}{\eta}\left(\frac{x}{\eta}\right)^{\beta-1} e^{-\left(\frac{x}{\eta}\right)^{\beta}}, & x \geq 0 \\ 0, & \text { else }\end{array}\right.$

6.3 Definition for Cumulative Distribution Function: Let $X$, be a random variable and

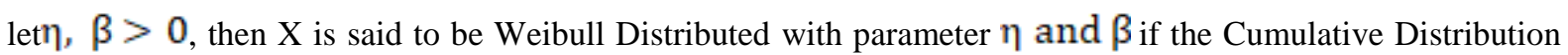

Function of $X$ is
$f(x: \eta, \beta)=\left\{\begin{array}{cl}1-e^{-\left(\frac{x}{\eta}\right)^{\beta}}, & x \geq 0 \\ 0, & \text { else }\end{array}\right.$

\subsection{Reliability Function}

The reliability function $R(t)$ provides the probability of survival over time $t$. Reliability function for Weibull distribution is

$\mathrm{R}(\mathrm{t})=\mathrm{e}^{-\left(\frac{\mathrm{t}-\gamma}{\eta}\right)^{\beta}}$

Also the reliability function can be calculated by doing the one minus from cumulative distribution function, i.e. $\mathrm{R}(\mathrm{t})=1-\mathrm{F}(\mathrm{t})$ 


\subsection{Hazard Function (Weibull failure rate function)}

The hazard function defines the instantaneous failure rate. For the distribution, the hazard function is given by:

$h(t)=\frac{f(t)}{R(t)}=\frac{\beta}{\eta}\left(\frac{t-\gamma}{\eta}\right)^{\beta-1}$

Depending on the values of the distribution's parameters, the Weibull's hazard function can be decreasing, (when $\beta<1$ ), constant (when $\beta=1$ at $\frac{1}{\eta}$ ), or increasing $($ when $\beta>1$ ) over time.

\subsection{Shape Parameter $-\beta$}

The parameter of shape (or power) regulates the overall density function shape. This amount usually varies from 0.5 to 8.0

If

$\boldsymbol{\beta}=\mathbf{1}$, The Weibull distribution (WD) is indistinguishable to the Exponential distribution(ED).

$\boldsymbol{\beta}=\mathbf{2}$, The WD is similar to the Rayleigh distribution (RD).

$\boldsymbol{\beta}=\mathbf{2 . 5}$, The WD approximates the lognormal distribution (LD).

$\boldsymbol{\beta}=\mathbf{3 . 6}$, The WD approximates the normal distribution (ND).

\subsection{Estimation of Parameters}

As discuss earlier, parameters of the Weibull distribution can be estimated through [Halil et al., 2010]

- Graphical Method via probability plotting paper

- Analytical Method, using method of least squares

- Analytical Method, using Maximum likelihood estimation method

\section{Experimental Analysis}

\subsection{Computational Estimation of Parameters of Weibull Distribution for the Collected Failure Data}

Figure 5 shows the computed analysis of the data in terms of parameters of Weibull distribution through MINITAB 19 for vehicle structure and compressor respectively. It is noted from the analyses for structure \& vehicle that the shape parameter $\beta=7.55926$ while scale parameter $\eta=695.651$ 


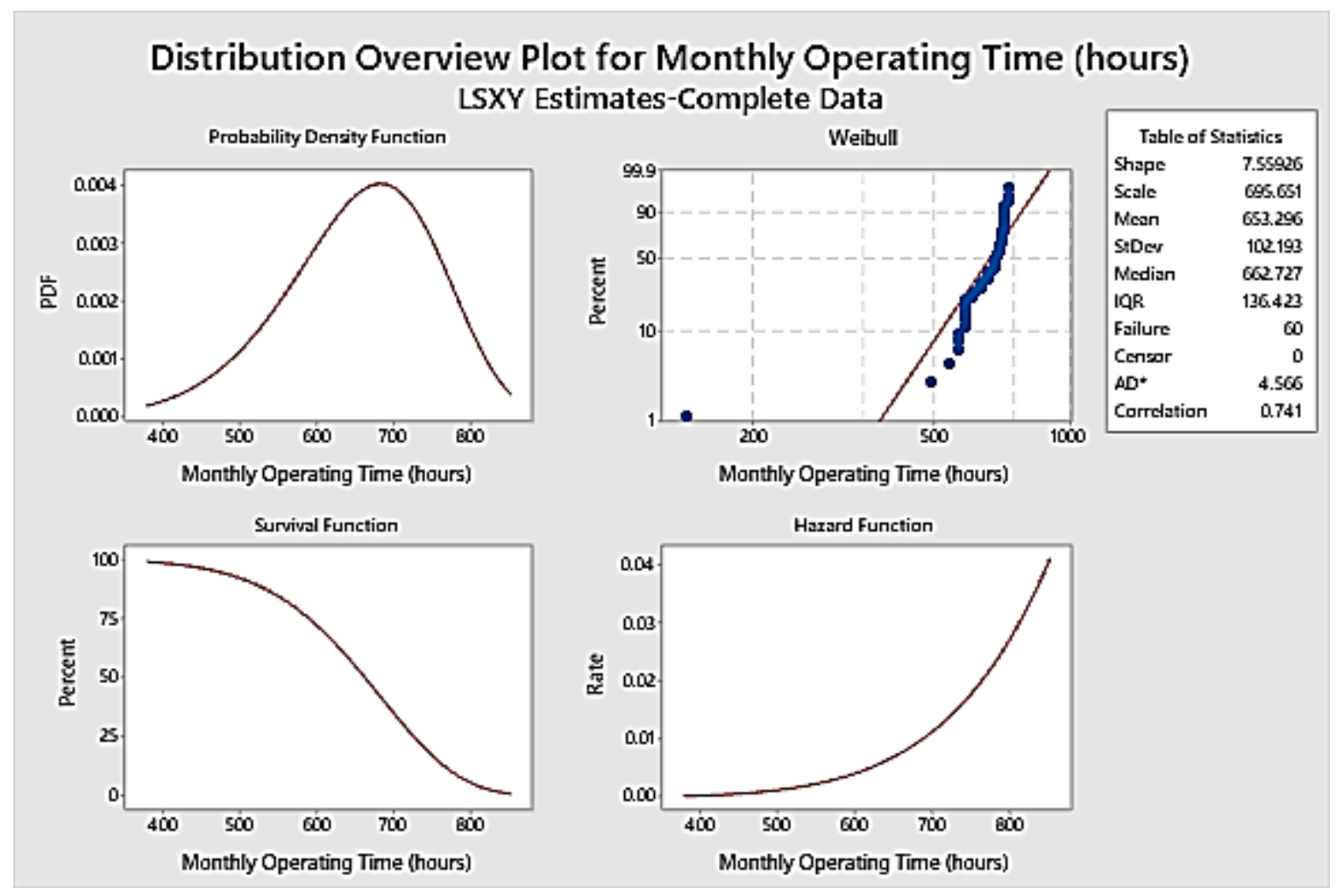

Fig. 5 - Distribution overview plot for monthly operating time - electrical control cabinet

\subsection{Estimated Reliability}

The reliability evaluation of the different components of the Railway Locomotive Engine includes the values of the shape parameters and also the reliability which emphasizes on the output of the Locomotive Engine parts during the period 2012-2016.

Table 5 - Reliability analysis for sub - systems (component)

\begin{tabular}{ccccc}
\hline Sub System & $\boldsymbol{\beta}$ & $\begin{array}{c}\text { Mean Value of } \\
\text { Operating hrs }\end{array}$ & $\begin{array}{c}\text { Estimated } \\
\text { Reliability }\end{array}$ & $\begin{array}{c}\text { Probability } \\
\text { for failure }\end{array}$ \\
\hline Electrical Misc. & 7.55926 & 656.467 & 59.999 & 39.378 \\
\hline
\end{tabular}

Table 6 - Shape parameter analysis

\begin{tabular}{ccc}
\hline Value of $\boldsymbol{\beta}$ & Possible Failure Mechanism & Cause of Failure \\
\hline$\beta>2$ & Pattern Related to Age & $\begin{array}{c}\text { Accelerated wear and tear of } \\
\text { Component }\end{array}$ \\
\hline$\beta \approx 1$ & Pattern Related to Time & $\begin{array}{c}\text { Faulty Design, Error in Process, } \\
\text { Malfunctions }\end{array}$ \\
\hline$\beta<1$ & Early Failure & $\begin{array}{c}\text { Fault of reconditioning and Fault in } \\
\text { Manufacturing }\end{array}$ \\
\hline
\end{tabular}




\subsection{Estimated Availability}

The availability is the probability that the system or framework would work accurately if required. Or, it is the probability that when it needs to be used, a system won't fail or undergo a repair action. It might seem at first glance that if a device has a high availability it should also have a high reliability [Avinash et al. 2019]. The simplistic expression of the availability is a combination of the expected value of the uptime and downtime of a network to the sum of the planned values

$$
A=\frac{E[\text { uptime }]}{E[\text { uptime }]+E[\text { downtime }]}
$$

Three different types of availability can be defined based on time

a) Availability (Inherent): It is the probability that a system (framework) or sub - system will work adequately at any instant when used under pre specified constraints in an optimal supportive environment. It includes downtime of corrective maintenance.

$$
A(i)=\frac{M T B F}{M T B F+M T T R}
$$

b) Availability (Achieved): It is the probability that a system or sub - system will work adequately at a given point in time when utilized under characterized conditions in an ideal strong condition i.e., personnel, tools, spares, and so on are easily accessible. It needs sufficient downtime for preventive and corrective maintenance.

$$
A(a)=\frac{M T B M}{M T B M+M T D}
$$

Where, MTBM is the mean downtime for active maintenance as a result of both corrective and preventive maintenance.

c) Availability (Operational): It is the probability that a system (framework) or sub - system will work adequately at a given point in time when utilized in a real or reasonable working operating and supportive conditional environment. This requires organizational resources, time available, and managerial downtime, and downtime in both preventive and corrective maintenance. It tends to be determined as

$$
A(o)=\frac{M T B F}{M T B F+M T D}
$$

where MTD is mean downtime .

Table 7 - Availability analysis for sub - systems (component)

\begin{tabular}{lc}
\hline Sub System & Availability \\
\hline Electrical Misc. & 0.996 \\
\hline
\end{tabular}

\subsection{Conclusion}

The article emphasizes on determining the reliability and availability of a particular locomotive as well as maintenance issues. Past data compilation is the most important prerequisite for performing these analyses. The initial stage of this article focuses on gathering well-defined data on the engine's failures and repairs. Inefficiency of workers, overloading, and degradation of components of the locomotive with respect to time are the factors which contributes in the failure of diesel locomotive engine. It has observed form the reliability estimation that the reliability of studied component is $59.999 \%$. The locomotive shed has no such appropriate supply of spare parts, such that the same can be immediately replaced. Whenever there is a malfunction, the repair department asks the shop, by indent, for a similar spare part. If the actual spare part is with the shop then it is shipped to the maintenance department otherwise an order will be put to buy department and thus the maintenance phase will be postponed due non-availability of the spare parts. It is important to examine the results of the preventive maintenance action on the components of the locomotive, regulating and tracking spare parts in terms of reliability aspects, in a detailed and continuous analysis. 


\section{Acknowledgement}

The authors are thankful to the "North Western Railway Diesel Locomotive Shed, Bhagat Ki Kothi, Jodhpur, Rajasthan, India” for providing the data regarding maintenance of diesel locomotive engine.

\section{References}

1) Bhardwaj, Sunil and Ashok Kumar and Vijay Bhardwaj (2019). Lifetime of Diesel Locomotive with Respect to Degradation Data (February 23, 2019). Available at [Elsevier-SSRN]:https://ssrn.com/abstract=3356680 or http://dx.doi.org/10.2139/ssrn.3356680

2) Sunil Bhardwaj, Nitin Bhardwaj, Vijay Kumar \& Bhupender Parashar (2019) Estimation of lifespan of diesel locomotive engine, Journal of Information and Optimization Sciences, 40:5, 1097-1108, DOI: 10.1080/02522667.2019.1641895

3) Sunil Bhardwaj, Nitin Bhardwaj, Vijay Kumar, The Study of Reliability of Diesel Locomotive Engine Using Weibull Distribution, INTERNATIONAL JOURNAL OF AGRICULTURAL AND STATISTICAL SCIENCES, Volume No. : 15 (2019) \& Issue No. : 02 (December), pp 549-554

4) Sunil Bhardwaj, Nitin Bhardwaj, Vijay Kumar, Weibull Distribution for the Prediction of System Reliability, FIRMS's International Journal of Mathematical Science, Vol 1 No 1 (2019)

5) Bhardwaj, Sunil, Vijay Kumar and Nitin Bhardwaj (2018). Reliability Analysis of Diesel Locomotive Engine. IJREAM [UGC approved], 04(04), ISSN 2454-9150

6) Sunil Bhardwaj, Nitin Bhardwaj, Vijay Kumar, The study of reliability of diesel locomotive engine using Weibull distribution, International journal of Agricultural and Statistical Sciences: P-ISSN: 0973-1903, e-ISSN: 09763392; Int. J. Agricult. Stat. Sci. Vol. 15, No. 2, pp. 549-554, 2019

7) India Railways Maintenance Manual for Diesel Locomotives, Revised Edition - December, 2013

8) Introduction Hand Book on General Motor Diesel Locomotive, Centre for Advance Maintenance Technology, Indian Railways, Gwalior

9) New Technologies Improving Aerodynamic Properties of Freight Vehicles / Tomas Skrucany, Stefania Semanova, Saša Milojević, Aleksandar Ašonja // Applied Engineering Letters : Journal of Engineering and Applied Sciences. - Vol. 4, No. 2 (2019), p. 48-54. (ISSN 2466-4677)

10) Li, Y.-F.; Center for System Reliability and Safety, University of Electronic Science and Technology of China, No. 2006, Xiyuan Avenue, West Hi-Tech Zone, Chengdu, Sichuan, China: ISSN: 09518320 - Elsevier: DOI: 10.1016/j.ress.2018.02.021

11) Babeł M, Szkoda M. Diesel locomotive efficiency and reliability improvement as a result of power unit load control system modernisation. Eksploatacja i Niezawodnosc -Maintenance and Reliability 2016; 18 (1): $38-49$, http://dx.doi.org/10.17531/ein.2016.1.6

12) Avinash Kumar Agarwal FSAE, FASME, FRSC, FNAE, FNASc, SBI Endowed Chair Professor, Engine Research Laboratory, Department of Mechanical Engineering, Indian Institute of Technology Kanpur: Railway Locomotive: Status, Challenges and Opportunities in India, 12th March 2019

13) Gediminas Vaičiūnas, Gintaras Gelumbickas, Diesel Trains Reliability Diversity Research, Procedia Engineering, Volume 134, 2016, Pages 95-100, ISSN 1877-7058, https://doi.org/10.1016/j.proeng.2016.01.044

14) Allan, T.M. (2012). Bayesian statistics applied to reliability analysis and prediction. Principal Engineering Fellow Report, Raytheon Missile Systems, Tucson, AZ

15) Dinkar B. Kishorilal, Alok K. Mukhopadhyay; Reliability investigation of diesel engines used in dumpers by the Bayesian approach; Kuwait Journal of Sciences, 45 (4) pp 15 - 2, 2018

16) Anderson, T.W. (2010). Anderson-Darling Tests of Goodness-of-Fit, Stanford University. Pp. 1-7

17) Emad, E. and Elmahdy \& Aboutahoun A.W. (2013). A new approach for parameter estimation of finite Weibull mixture distributions for reliability modelling. Applied Mathematics Modelling, 37: 1800-1810

18) Halil, A., Birdal, S.\& Mahmut, K. (2010). Parameter estimation in geometric process with Weibull distribution. Applied Mathematics Computation, 217(6): 2657-2665

19) Venkatesh, M. (2012). Failure rate analysis of IC engine subsystems. International Journal of Modern Engineering Research, 2(5): 3320-3328

20) Shazaib Ahsan, Tamiru A. Lemma, Mebrahitom A., Reliability analysis of gas turbine engine by means of bathtubshaped failure rate distribution, Proc Safety Prog. 2019; e12115. wileyonlinelibrary.com/journal/prs (C) 2019 American Institute of Chemical Engineers 1 of 10 